\title{
PERCEPTION AND KNOWLEDGE ABOUT HIV/AIDS AMONG STUDENTS IN A MEDICAL COLLEGE IN WESTERN NEPAL
}

\author{
Shankar PR ${ }^{1}$, Subish $\mathrm{P}^{2}$, Paudel $\mathrm{R}^{3}$, Alam $\mathrm{K}^{4}$ \\ 'Department of Clinical Pharmacology, KIST Medical College, Lalitpur, Nepal \\ ${ }^{2}$ Department of Pharmacology, Manipal College of Medical Sciences, Pokhara, Nepal \\ ${ }^{3}$ Department of Medicine, Manipal College of Medical Sciences, Pokhara, Nepal \\ ${ }^{4}$ Department of Pharmacology, Manipal College of Medical Sciences, Pokhara, Nepal.
}

\section{ABSTRACT}

Background : Medical students are taught about HIVIAIDS throughout the curriculum. The objectives of the present study were:

a) To study the perceptions and knowledge of medical students regarding HIV/AIDS

b) Obtain information on lacunae observed and.

c) Compare the median scores among different subgroups

Methods : The study was carried out among the first, third, (preclinical) and fifth and sixth semester (clinical) students at the Manipal College of Medical Sciences, Pokhara, Nepal. The students were explained the objective of the study and invited to participate. Written informed consent was obtained. Student perception regarding HIVIAIDS was studied by noting their degree of agreement with a set of 22 statements using a modified Likert-type scale. The median score was compared among different subgroups.

Results : 163 students participated. The median score was 77 (maximum score 110). The median score was significantly higher among Nepalese students compared to other nationalities $(p=0.000)$ and among the scholarship students compared to the self-financing $(p=0.000)$. The free text comments stressed the importance of safe sex in controlling HIVIAIDS.

Conclusion : The overall scores were high. The lacunae observed can be addressed through educational interventions. The foreign and the self-financing students need greater training to tackle HIVIAIDS. The study had many limitations which may affect its generalizability and representativeness and more detailed studies are required.

Key words : HIVIAIDS, Knowledge, Medical students, Nepal, Perceptions

\section{INTRODUCTION}

Acquired immunodeficiency syndrome (AIDS) was first diagnosed in the United States (US) in 1981; over 90\% of all infected cases occur in developing countries and the number of cases is increasing every year. ${ }^{1}$ AIDS can provoke irrational emotions and fears in healthcare

\section{Correspondence to}

Dr. P. Ravi Shankar

KIST Medical College

P.O. Box 14142 Kathmandu, Nepal.

Fax: 977-1-5201496 E-mail: ravi.dr.shankar@gmail.com providers, including medical students. These fears may act as barriers to successful educational efforts about the diseases and lead to adverse outcomes. ${ }^{2}$ In Nepal, limited data indicate that Human immunodeficiency virus (HIV) prevalence is around 0.5 percent in the adult population between the ages of $15-49$ with a male female ratio of approximately $3: 1 .^{3}$

HIVIAIDS is becoming an important problem in Nepal and South Asia. Young and productive age groups of the population are at the center of the HIV epidemic in Nepal. ${ }^{4}$ Since 1997 , the disease has been spreading rapidly among intravenous drug users and commercial sex workers. The 
author had called for a national response in terms of both HIV prevention and care. ${ }^{5}$ There was a violent ten-year conflict in Nepal. The authors of a recent article state that the violent conflict may have fuelled the HIVIAIDS epidemic in Nepal. ${ }^{6}$

The Manipal College of Medical Sciences (MCOMS), Pokhara is affiliated to the Kathmandu University for the undergraduate medical (MBBS) course. The college admits students from Nepal, India, Sri Lanka and a few students from other countries. The basic science subjects are taught during the first four semesters and the clinical subjects from the fifth semester. HIVIAIDS is covered in an integrated manner during both the basic science and clinical semesters. Medical students as future doctors will play an important role in caring for HIVIAIDS patients. Also medical students belong to the young and vulnerable age group of the population and their behavior may put them at risk of HIVIAIDS and sexually transmitted diseases. Knowledge and perceptions of students about HIVIAIDS should be assessed so that appropriate changes in the teachinglearning methodology can be carried out, if needed.

Hence the present study was carried out with the following objectives.

a) To study the perceptions and knowledge of medical students regarding HIVIAIDS

b) Obtain information on lacunae observed so that appropriate teaching-learning programs can be initiated and

c) Compare the median scores among different subgroups

\section{METHODS}

The study was carried out among first, third, fifth and sixth semester undergraduate medical (MBBS) students at the Manipal College of Medical Sciences, Pokhara, Nepal during the month of July 2008. The first and third semester students were in the Basic Science years while the fifth and sixth semesters were in the clinical years. The study were explained the objectives of the study and invited to participate. Written informed consent was obtained from all the study participants.

Basic demographic information like gender, nationality, semester of study, occupation of parents, method of financing of medical education and whether the student hailed from an urban or rural area were noted. Perception and knowledge about HIVIAIDS was obtained by noting the respondents' degree of agreementwith a set of 22 statements using a modified Likert-type scale. The statements dealt with general information about HIV infection, prevention of infection, diagnosis and treatment. The questionnaire used is shown in the Appendix. Statements 2, 3, 4, 6, 7, 8, 12 and 17 were negative and their scores were reversed to calculate the total score.

The median total score was calculated. The median scores of individual statements were also worked out. The median total score was compared among different categories of respondents. Mann-Whitney test was used for dichotomous variables and Kruskal-Wallis test for the others. A p value less than 0.05 was taken as statistically significant. Free text comments were invited from the respondents and the common comments were noted.

\section{RESULTS}

A total of 163 students participated in the study. The total number of students in the four semesters was 275 giving a response rate of $59.3 \%$. Twenty-eight students were from the first semester, 50 from the third, 47 from the fifth and 37 from the sixth semester participated. The response rates of the first semester was $56 \%$ (28 of the 50 students), of the third semester was $66.6 \%$ (50 of the 75 students). For the fifth and sixth semester the rates were 62.7 and $49.3 \%$ respectively.

Table 1 shows the demographic characteristics of the respondents. Nepalese and Indians were the major nationalities. Male students were more and few students had doctor parents. Majority of students were self-financing.

Table 1: Demographic characteristics of the respondents

Characteristic

Semester of study First

Third

Fifth

Sixth

$50(30.7)$

47 (28.8)

38 (23.3)

Nationality

Nepalese

Indian

Sri Lankans

75 (46)

64 (39.3)

Others

$16(9.8)$

Gender

Male

$3(1.8)$

Female

48 (29.4) 


\begin{tabular}{|l|l|} 
Occupation of father & \\
Doctor & $39(23.9)$ \\
Others & $114(69.9)$ \\
Occupation of mother & \\
Doctor & $17(10.4)$ \\
Others & $40(24.50$ \\
Housewife & $97(59.5)$ \\
Method of selection & \\
Govt. selected & $50(30.7)$ \\
Self-financing & $106(65)$ \\
\hline Place of origin & \\
Urban & $126(77.3)$ \\
Rural & $21(12.9)$ \\
\hline
\end{tabular}

The median total score was 77 (maximum possible score 110). The interquartile range was 11. Table 2 shows the median total scores of individual statements. Many respondents were under the impression that HIVIAIDS is a more dangerous disease than hepatitis $B$. The respondents were equivocal about the statement 'HAART is effective in treating HIVIAIDS' and about enrolling them and their family enrolling children in a school which admits HIV-positive children. They were in agreement that homosexuality was a crime against God and humanity. The scores of statements 18,19 and 20 were very high.

\section{Table 2 : Median scores of individual statements}

\begin{tabular}{|l|l|}
\hline Statement number & Median score \\
\hline One & Four \\
\hline Three & Four \\
\hline Four & Four \\
Five & Two \\
Six & Four \\
Seven & Four \\
\hline Eight & Four \\
\hline Nine & Four \\
\hline Ten & Three \\
Eleven & Four \\
\hline Twelve & Three \\
\hline Thirteen & Two \\
\hline Fourteen & Four \\
\hline Fifteen & Four \\
\hline Sixteen & Four \\
\hline Seventeen & Four \\
\hline Eighteen & Four \\
Nineteen & Five \\
\hline Twenty & Five \\
\hline Twenty-one & Five \\
\hline Twenty-two & Four \\
\hline
\end{tabular}

Table 3 shows median total scores among certain selected subgroups of respondents. The median score was higher among Nepalese students compared to other nationalities. Surprisingly, students whose mother's occupation was a doctor had lower scores. Scholarship students had higher scores compared to self-financing ones.

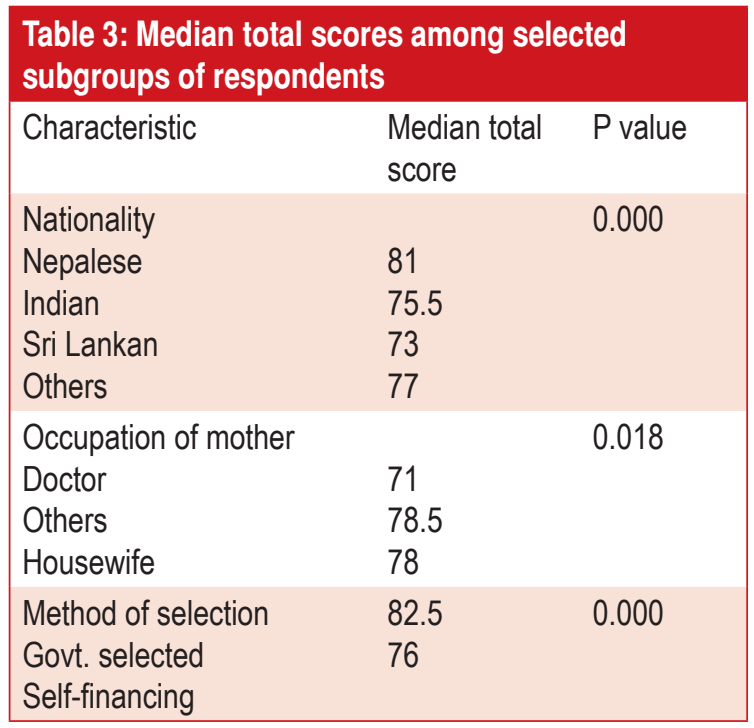

The free text comments stressed the importance of safe sex in controlling HIVIAIDS. Sex education in schools was felt to be important in controlling the epidemic. The respondents were happy that this important issue was being studied by the investigators.

\section{DISCUSSION}

The overall knowledge of the medical students surveyed was good. Certain lacunae were observed and the knowledge and perception among certain subgroups of students was low.

Knowledge about HIVIAIDS is important among medical students because of its increasing prevalence. Medical students should be able to protect themselves against HIV infection during practice. Their perception is important as medical students should be able to provide treatment to AIDS patients. They also have an important role in educating the public about HIVIAIDS. A previous study done in 1999 had revealed AIDS phobia among medical students and the authors had suggested that medical educators help students overcome the phobia. ${ }^{2}$ Studies have been carried out among the general population, non-medical and medical students in various countries. A study was carried out on knowledge and beliefs about HIVIAIDS among young people in urban Nepal. ${ }^{7}$ The 
authors concluded that knowledge of the disease was very high. Married people and females had lesser knowledge than others. Knowledge, attitude and practice regarding HIVIAIDS was studied among the general population in Dakshina Kannada district of Karnataka, India. ${ }^{8}$ Significant gaps in knowledge were noted. Male gender, higher education, currently married and reading newspapers were associated with higher scores.

Chinese students were surveyed using a questionnaire for knowledge of and attitudes about HIVIAIDS. ${ }^{9}$ Students obtained information about HIVIAIDS from a variety of sources and had a moderate level of knowledge about the condition. Medical students had better knowledge and attitudes than others. Educational programs about sex and sexually transmitted diseases were recommended with medical students playing an important role. ${ }^{9} \mathrm{~A}$ recent study had found that the knowledge, attitude and practice (KAP) of university students about HIVIAIDS was impressive. ${ }^{4}$ The authors had recommended voluntary counseling and testing (VCT) services. Misconceptions like HIV is transmitted by sharing of food were also prevalent. A study was carried out to determine the level of awareness of medical students regarding HIVIAIDS, hepatitis B and C. ${ }^{10}$ Various misconceptions were noted and the authors concluded that there is a lack of awareness among medical students. Universal precautions should be emphasized.

In the present study the students were under the misconception that HIVIAIDS is a more dangerous disease than hepatitis $B$. The respondents were equivocal about admitting their or their family's children in a school which admits HIV positive children. This correlates with the finding in a study in Pakistan where over half the respondents felt that HIV-positive students should be excluded from government schools. ${ }^{11}$ Over $30 \%$ would avoid someone with HIVIAIDS. Students agreed with the statement that homosexuality is a crime. This may reflect the conservative nature of South Asian society where alternative sexual preferences are not accepted. In a study in England, students felt that patients with HIV infection were themselves to blame, some did not deserve treatment and homosexuality could not be accepted as part of a normal lifestyle. ${ }^{12}$ Students totally agreed with the statement about coinfection with HIV and TB leading to more severe forms of the two disease, about wider availability of condoms and sex education in schools. A survey carried out in India among new medical students had shown good knowledge and few misconceptions about HIVIAIDS. ${ }^{13}$
In Zagreb, Croatia attitudes towards HIVIAIDS was studied among fourth year medical students during 2002/03 and compared with those to a previously reported one among 1993/4 students. ${ }^{14}$ The 2002/03 students had a higher core. Less homophobia, better knowledge about transmission and experience with HIVIAIDS patients were associated with a better attitude. In the present study Nepalese students, students who did not have doctor parents and government selected scholarship students had higher scores. All the scholarship students are Nepalese and the Nepalese self-financing students are selected through an entrance examination conducted by Kathmandu University. Nepalese students perform better academically compared to students of other nationalities. The finding that students with either parent a doctor has lower scores is surprising and difficult to explain. Differences in knowledge and attitude were noted in previous studies. In the British study, Cambridge students had better knowledge about HIVIAIDS than their London counterparts. ${ }^{12}$ The Cambridge students however, had a more negative attitude. Differences were noted among subgroups of pharmacy students in a survey in Malaysia. ${ }^{1}$ In Pakistan, older students and clinical students were more knowledgeable compared to others. ${ }^{11}$ In MCOMS, there was no difference in the knowledge and perception score among preclinical and clinical students.

Certain lacunae in knowledge and perception were noted. Foreign students and self-financing students had lower scores. Educational interventions can be recommended to correct the lacunae. In Nigeria, systematized HIVIAIDS education for student nurses resulted in favorable changes in knowledge and attitude. ${ }^{15}$ They were more likely to comply with universal precautions. In Iran, an educational course significantly improved the knowledge and attitude of students towards HIVIAIDS. ${ }^{16}$ A Mexican study had looked at teaching of HIVIAIDS in a sample of medical schools. Only $20 \%$ of the curricula included teaching of the subject, an average of 8.8 hours only was assigned to its teaching and over $90 \%$ of professors involved in teaching had no clinical experience in the field. ${ }^{17}$ In MCOMS, though the subject is covered during various semesters of study, the teaching is largely theoretical. Social aspects like telling a patient that he/she is HIV-positive, the social aspects of the disease and preventive health education are not emphasized. Studies among other semesters are needed to find out whether there continues to be lacunae in knowledge among foreign and self-financing students. 
The study had limitations. The questionnaire was pretested among three students from other semesters for readability and comprehensibility. Detailed pretesting was not carried out. The practice of students regarding HIVIAIDS was not studied. Only certain selected aspects of the topic were covered in the questionnaire. The response rate especially of the sixth semester students was low. The study was carried out only among certain semesters of students in a single medical school in Nepal. These factors may affect the generalizability and representativeness of the study. This study can be considered as a preliminary one and the authors are considering conducting a much stronger representative study using an improved questionnaire among different semesters of medical students in more number of Nepalese medical schools.

\section{CONCLUSIONS}

The overall scores were high but certain misconceptions were noted. The misconceptions should be corrected through education. The scores among foreign and selffinancing students were lower compared to the Nepalese. These students may need more education and training on the subject. Studies among other semesters of students and in other Nepalese medical schools should be carried out.

\section{ACKNOWLEDGEMENTS}

The authors acknowledge the support of non-teaching staff of the department of Pharmacology, MCOMS while carrying out the study. The authors thank all the students who participated.

\section{REFERENCES}

1 Ahmed SI, Hassali MA, Aziz NA. An assessment of the knowledge, attitudes, and risk perceptions of pharmacy students regarding HIVIAIDS. American Journal of Pharmaceutical Education 2009;73:Article 15.

2 Kopacz DR, Grossman LS, Klamen DL. Medicals tudents and AIDS: Knowledge, attitudes and implications for education. Health Education Research 1999;14:1-6.

3 National Centre for AIDS and Sexually Transmitted Infection Control (NCASC) Nepal's- National HIVIAIDS Strategy, Ministry of Health, GoN, Nepal. 2002.

4 Joshi DR, Khatri DB, Rosyara KP, Malla B. Do behavioral patterns of university students of Nepal make them vulnerable to HIVIAIDS? Journal of Institute of Medicine 2007;29 (3):1317.
5 Suvedi BK. The AIDS situation in Nepal. Journal of Health Management 2003;5:205-13.

6 Singh S, Mills E, Honeyman S, Suvedi BK, Pant NP. HIV in Nepal: Is the violent conflict fuelling the epidemic? PLoS Medicine 2005;2:e216.

7 Neupane S, Nichols D, Thapa S. Knowledge and beliefs about HIVIAIDS among young people in urban Nepal. AsiaPacific Population Journal 2003;18:39-52.

8 Meundi AD, Amma A, Rao A, Shetty S, Shetty AK. CrossSectional Population-Based Study of Knowledge, Attitudes, and Practices Regarding HIVIAIDS in Dakshina Kannada District of Karnataka, India. Journal of the International Association of Physicians in AIDS Care 2008;7:27-34.

9 Tan X. Results of a questionnaire survey among Chinese students on knowledge of and attitudes about HIVIAIDS. Medical Education 2008;42:227.

10 Anjum Q, Siddiqui $H$, Ahmed $Y$, Rizvi SR, Usman $Y$. Knowledge of students regarding hepatitis and HIVIAIDS of a private medical university in Karachi. Journal of Pakistan Medical Association 2005;55:285-8.

11 Shaikh FD, Khan SA, Ross MW, Grimes RM. Knowledge and attitudes of Pakistani medical students towards HIV-positive and/or AIDS patients. Psychology Health and Medicine 2007;12:7-17.

12 Evans JK, Bingham JS, Pratt K, Carne CA. Attitudes of medical students to HIV and AIDS. Genitourinary Medicine 1993:69:377-80.

13 Basavayya GS, Sai TS, Kolli SK. Awareness of HIV/ AIDS among medical students. Indian J Public Health. 2005;49:32-3.

14 Tesić V, Kolarić B, Begovac J. Attitudes towards HIVIAIDS among four year medical students at the University of Zagreb Medical School--better in 2002 than in 1993 but still unfavorable. Coll Antropol. 2006;30(Suppl 2):89-97.

15 Uwakwe CBU. Systematized HIVIAIDS education for student nurses at the University of Ibadan, Nigeria: impact on knowledge, attitudes and compliance with universal precautions.

16 Jodati AR, Nourabadi GR, Hassanzadeh S, Dastgiri S, Sedaghat K. Impact of education in promoting the knowledge of and attitude to HIVIAIDS prevention: a trial on 17,000 Iranian students. Int J STD AIDS. 2007;18:407-9.

17 Izazola-Licea JA, Volkow-Fernández P, Sierra-Madero J, Avila-Figueroa C, Herrera-Basto EA. Teaching and including HIVIAIDS in the curricula of a medical school sample in Mexico. Gac Med Mex. 2005;141:483-8. 


\section{Appendix: Questionnaire used for the study \\ Perception and Knowledge regarding HIV/AIDS among students in a medical college in Western Nepal}

Semester of study:

Occupation of father:

Govt. selected/Self-financing:
Nationality:

Occupation of mother:
Gender:

Urban/Rural

For the following statements score using the following key $(1=$ strongly disagree with the statement, $2=$ disagree with the statement, $3=$ neutral, $4=$ agree with the statement, $5=$ strongly agrees with the statement.) Use whole numbers only.

1 HIVIAIDS is a major health and social problem and has the potential to derail the rapid economic growth being achieved.

2 Drugs are available which can cure HIVIAIDS.

3 AIDS is exclusively a disease of homosexuals and cannot affect theterosexuals.

4 In terms of infectivity, HIVIAIDS is a more dangerous disease than hepatitis $B$.

5 In my future career, I will be comfortable treating AIDS patients.

6 The basic genetic material of the virus causing HIV is deoxyribonucleic acid.

7 Oral contraceptives can prevent the transmission of HIV.

8 Sharing eating utensils with a HIV positive patient can lead to transmission of the disease.

9 HAART is effective in treating HIVIAIDS.

10 Barber shops and beauty parlors can serve as an important means of spread of HIV.

11 I and my immediate family have no problems enrolling our children in a school which admits HIV positive children.

12 Homosexuality is a crime against God and humanity.

13 Using a condom during sexual intercourse is a reliable protection against HIVIAIDS.

14 Antiretroviral drugs have a high risk of drug interactions.

15 Patent issues and cost are important factors hindering access to newer antiretrovirals.

16 I am comfortable being friends with a HIV positive person.

17 A HIV positive person can safely donate blood.

18 Co infection with HIV and TB can lead to more severe manifestation of both diseases.

19 Condoms should be widely available and condom vending machines should be installed in public places.

20 Sex education in schools can reduce the transmission of HIV.

21 CD4 count is of prognostic importance in HIV infection.

22 Directly observed treatment can be useful in improving compliance in HIV infection.

Any other comments (Please use the back of the sheet) :

Thank You for participating. It is very much appreciated. 